\title{
Rheological Behavior of Some Starch - Based Bioplastics
}

\author{
Elena Mihaela NAGY ${ }^{1,2^{*}}$, Mihai TODICA ${ }^{1}$, Razvan STEFAN ${ }^{3}$, Constantin COȚA ${ }^{2}$, Nicolae CIOICA ${ }^{2}$, Viorel \\ Cornel POP ${ }^{1}$, Loredana Elena OLAR ${ }^{4}$, Ionel PAPUC ${ }^{4}$ \\ ${ }^{1}$ Dep. of Condensed State Physics and Advanced Technologies, “Babes-Bolyai” University, Cluj-Napoca, \\ Romania. \\ ${ }^{2}$ INMA Bucharest, Branch of Cluj-Napoca, Romania; \\ ${ }^{3}$ Dep. I Preclinic, University of Agricultural Sciences and Veterinary Medicine, Cluj-Napoca, Romania \\ ${ }^{4}$ Dep. II Preclinic, University of Agricultural Sciences and Veterinary Medicine, Cluj-Napoca, Romania \\ *corresponding author, e-mail: nagy_m2002@yahoo.co.uk
}

Bulletin UASVM series Agriculture 73(1)/2016

Print ISSN 1843-5246; Electronic ISSN 1843-5386

DOI 10.15835/buasvmcn-agr: 12011

\begin{abstract}
The recent interest in the field of bioplastics is to obtain packaging material from pure starch without synthetic polymers. The rheological behaviour represents one of the most important feature of such materials. Samples with different ratio of starch, glycerol and water were prepared and investigate regarding their rheological behaviour. After the samples reaches their limit of swelling and were completely decomposed viscosity was measured with a Brookfield DV-III Ultra rheometer at different temperatures and share rates. The data were analyzed with Kaleidagraph software. For a given sample our measurements show that the viscosity is dependent on share rate and switches from a non-Newtonian to a Newtonian behaviour in function of temperature and sample composition. We used the power law model to describe this dependence and for a given set of data there is only one output for the fit parameters. We consider the best fit of the experimental data when the curve traced by the computer passes almost through all experimental points. In the present research work we establish a particular algorithm of mathematical analysis of experimental data which allows a separation of the contribution of each variable to the viscosity.
\end{abstract}

Keywords: power law model, rheological behaviour, starch-based bioplastics.

\section{INTRODUCTION}

Synthetic polymers are indispensable to our modern life due to their wide range of applications from packaging, agriculture, food to building materials, industry, etc. The resistance of synthetic polymers to different degradation factors has become a serious concern and as a consequence time resistant polymeric wastes are becoming less and less acceptable (Vert M. et all. 2002).

In recent years, all over the world, it has increased the concern regarding the increasing difficulties of plastic waste disposal caused by the non -biodegradability of the synthetic polymers, one of the main means of pollution of water and soil.

Research and development activities conducted worldwide to identify alternative raw materials that can be use to ensure an environmentally -friendly nature of plastics materials revealed starch based biopolymers as a possible solution to the environmental problem concerning the plastic waste disposal and reducing of oil resources (Rosa D. S., et all. 2008). Starch basede bioplastics represent $85-90 \%$ of market's bioplastics (Bastioli, C., 2000).The target of recent investigations in the field of bioplastics is to 
obtain packaging material from pure starch and to exclude synthetic polymers from the formulation (Mitrus M., Moscicki L., 2014).

Native starch exists in a semicrystalline granule and is comprised of two polysaccharides: amylase and amylopectine. Due to the intra- and intermolecular hydrogen bonds between the hydroxyl groups in starch molecules, the native starches are not thermoplastic compounds, but in the presence of a plasticizer (water, glycerol, sorbitol, etc.), of high temperature $\left(90^{\circ}-180^{\circ} \mathrm{C}\right)$ and subjected to mixing-shearing processes it melts and becomes fluid, providing possibility of use with extrusion, injection, blowing equipment, similar to those used for synthetic plastic materials. Due to their low resistance to water and low strength, the use of materials made only from starch is limited.

This paper presents the rheological investigations for some starch-based packaging materials obtained by thermoplastic extrusion of native starch, (with an amylase content of 21\%), with different starch, glycerol and water ratios, subjected to natural degradation after absorption of distillate water and a particular algorithm of mathematical analysis of experimental data which allows a separation of the contribution of each variable to the viscosity.

\section{MATERIALS AND METHODS}

The normal corn starch used in this study was obtained from SC Amylon SA Sibiu, Romania. The initial water content of starch on wet basis (wt.b) was $10.76 \%$ and the density was $0.561 \mathrm{~g} / \mathrm{cm}^{3}$. The amylase content was $21 \%$. The glycerol was purchased from SC Nordic Invest SRL Cluj Napoca and had a concentration of $99.5 \%$ and a density of $1.262 \mathrm{~g} / \mathrm{cm}^{3}$. The water used was from the water supply system. The composition of samples is shown in Table 1.

For rheological measurement we prepare different samples, the quantities of packaging

Tab. 1. The ratio of the components starchglycerol-water in the used formulas

\begin{tabular}{cccc}
\hline Sample & $\begin{array}{c}\text { Starch } \\
{[\%]}\end{array}$ & $\begin{array}{c}\text { Glycerol } \\
{[\%]}\end{array}$ & $\begin{array}{c}\text { Water } \\
{[\%]}\end{array}$ \\
\hline P1 & 78 & 19.5 & 2.5 \\
\hline P2 & 68 & 17 & 15 \\
\hline
\end{tabular}

sample and distilled water used are presented in Table 2.

The rheological measurements were performed using the Brookfield DV-III Ultra programmable rheometer with 0.01-250 RPM and precision of $+/-1,0 \%$. To determine the viscosity at different temperatures the samples were heated in TC150SD Brookfield Circulating Bath, with standard digital controller, temperature measuring range between $10-150{ }^{\circ} \mathrm{C}$. Viscosity was measured at different temperature (35 to 50 ${ }^{\circ} \mathrm{C}$ ) for each sample. After each measurement we check the total weight of the sample (container, sample and water) and water lost by evaporation was completed to attain initial weight (Table 2). The data were analyzed with Kaleidagraph software.

We measured the viscosity after the samples reaches their limit of swelling and was completely decompose. For the sample P1, (content of 78/19.5/2.5 starch / glycerol / water), the completely swelling was observed after five days, and for the sample P2, (containing starch / glycerol / water ratio of 68/17/15), after one day (Nagy, E.M., et all., 2015).

To observe the contribution of each variable to the viscosity the experimental data were analyzed usig the power model. Some works were reported on literature on similar system but the formula of the samples and the method of investigation are different.

\section{RESULTS AND DISCUSSIONS}

Figure 1 present the variation of viscosity for sample P1 (with 78/19/2.5 starch/glycerol/ water ratio), at 35,45 and $50{ }^{\circ} \mathrm{C}$ and for share rates between 5-200 rot/min. The measurements were performed for the packaging sample degraded in

Tab. 2. The quantities of packaging sample and distilled water used for rheological measurements

\begin{tabular}{cccc}
\hline Packaging & Dry sample \\
sample & $\begin{array}{c}\text { Distilled } \\
\text { water } \\
{[\mathrm{g}]}\end{array}$ & $\begin{array}{c}\text { Initial } \\
\text { weight of the } \\
\text { recipient, } \\
\text { sample and } \\
\text { water } \\
{[\mathrm{g}]}\end{array}$ \\
\hline P1 & 22.79 & 42.82 & 93.17 \\
\hline P2 & 0.91 & 20.00 & 48.47 \\
\hline
\end{tabular}


water for five days. The rheological measurements for this sample show that at low temperature $\left(35^{\circ} \mathrm{C}\right)$ the dependence between viscosity and share rate tends to linearity in the interval 20-200 rot/min. When the temperature increases $\left(50{ }^{\circ} \mathrm{C}\right)$ there is a dependence of viscosity function of shear rate which does not comply with the Newtonian model (Nagy, E.M., et all., 2015).

For the sample P2 (with starch / glycerol / water ratio of $68 / 17 / 15$ ) the measurements were performed for the colloidal solution resulted from the degradation of package sample in distilled water (figure 2). The measurement were made in same conditions at 35,45 and $50{ }^{\circ} \mathrm{C}$ and for share rates between 5-200 rot/min. For all the temperatures, at low shear rate, 20-50 rot/min the dependence between viscosity and share rate does not comply with the Newtonian model, but this dependence tends to linearity in the interval 50-200 rot/min (Nagy, E.M., et all., 2015).

Switching from a non-Newtonian behavior to a Newtonian one indicates that the large conglomerates of polymeric structures transforms in smaller elements with spherical symmetry, characteristic of simple Newtonian liquids. It is clear evidence of degradation (Todica M., 2005).

To describe the dependence of viscosity on share rate we used data obtained for sample P2 (starch/glycerol/water: 68/17/15) due to its fast degradation in water, which is our goal for this packaging material based on native starch.

For a given temperature we observed a decrease of the viscosity with the increase of shear rate (fig.2).

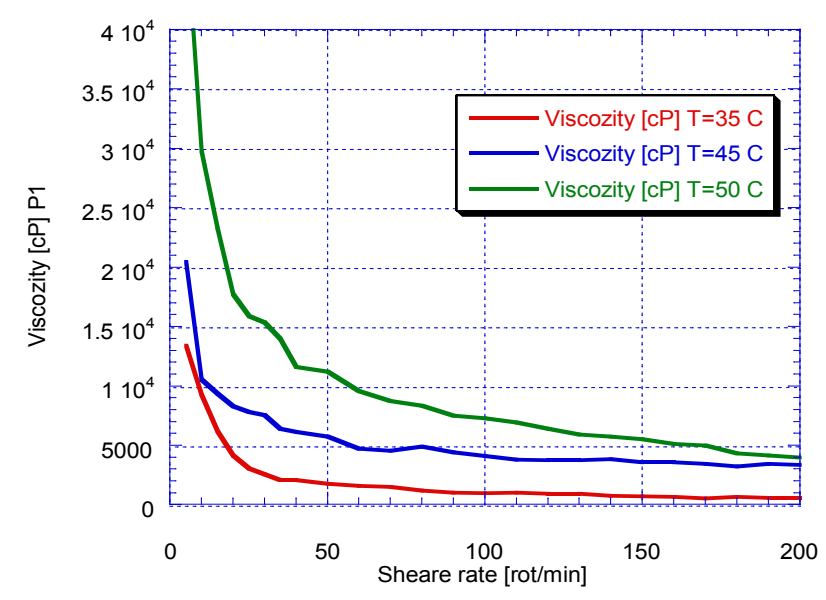

Fig. 1. Viscosity variation with share rate - sample P1(78/19/2.5 starch/glycerol/water ratio) at different temperatures

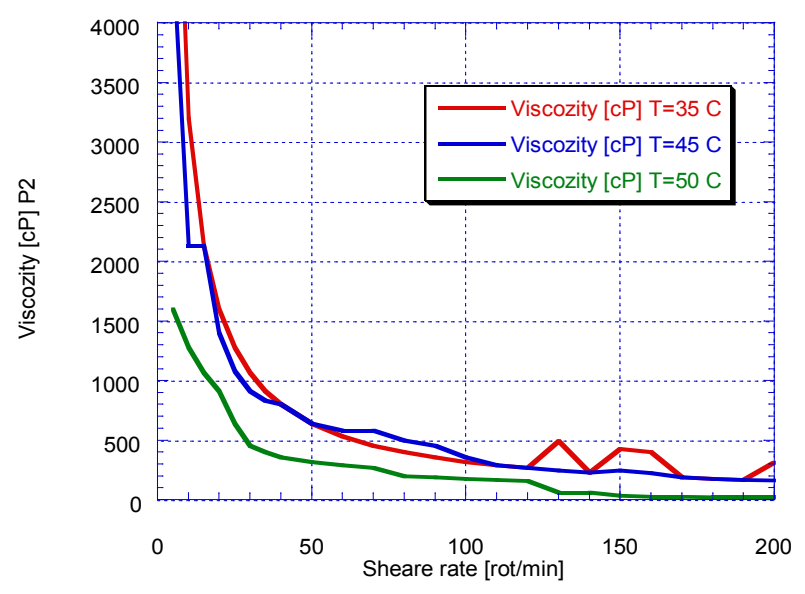

Fig. 2. Viscosity variation with temperature and share rate - sample P2 (starch / glycerol / water ratio of 68/17/15) 
Usually a simple mathematical model, power law, is used for preliminary analysis. The equation describing the dependence beetwen viscosity and share rate is:

$\eta=a(\text { 国 })^{x}$

where $\eta$ represents the viscosity, ? represents the share rate, $x$ is the power exponent and $a$ is a proportionality parameter. We used this equation to approximate the dependence on share rate for our experimental data.

At constant concentration, but different temperatures, the conformation of polymeric chains change due to the termal agitation. Every change in conformation request a quantity of energy, this effect being reflected by the dependence of the the factor $a$ on temperature, $a(T, \Phi)$.

To find a simple mathematical function we can consider that at constant rotation speed the factor ( Q ?) $)^{x}$ is constant (parameter $x$ is independent on the temperature at constant concentration), (? $)^{x}=$ $B=$ const.

The dependence of the viscosity on temperature is expressed by the Arrhenius law [2].

$\eta=C(\Phi) \exp \left(E_{d} / R T\right) B$

where $E_{a}$ is the activation energy on the flow, $R$ is the universal constant of gases and $C(\Phi)$ is a proportionality factor containing the contribution of concentration. From (1) and (2) we can write:

$a(T, \Phi)=C(\Phi) \exp \left(E_{a} / R T\right)$

Combining the two dependence, on temperature ec. (3) and on shear rate ec. (1) we can write the equation for the viscosity :

$$
\eta(\Phi, T, \text { 目 })=C(\Phi) \exp \left(E_{a} / R T\right)(\text { 目 })^{x}
$$

This equation describe in a mathematical formula the dependence of viscosity on temperature, concentration and share rate. The contribution of temperature is contained in the exponential factor, the contribution of concentration is containd in the function $C(\Phi), x$ and $E_{a}$ and the contribution of share rate in the power factor.

We used the equation (4) to fit the experimental data representing the variation of viscosity vs. share rate, at different temperature, for sample P2.

Due to the small differences between the value of $C(\Phi)(C(\Phi)=\mathrm{m} 1)$ we consider that it has a weak temperature dependence so that in a first approximation we consider $C(\Phi)$ constant.

The advantage of eq.(4) is the possibility to separate the contribution of share rate, concentration and temperature to the viscosity, in this way the equation could be helpful to the study of polymeric flow.

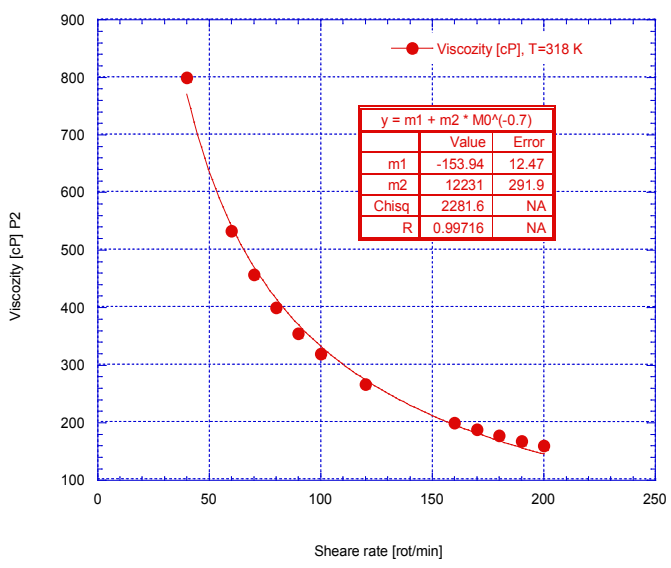

a)

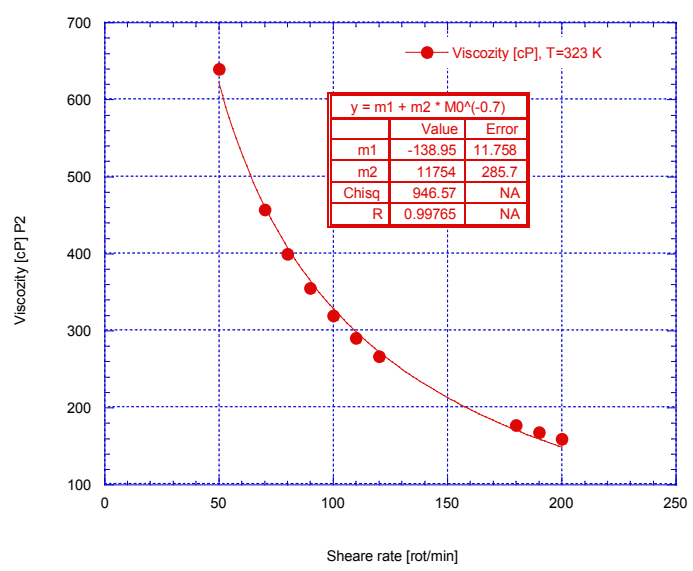

b)

Fig. 3. Fit with eq.(4) of experimental data representing the variation of viscosity vs. share rate, at different temperature (a) for $45^{\circ} \mathrm{C}$, b) for $50{ }^{\circ} \mathrm{C}$ ), for sample P2

(with starch / glycerol / water ratio of 68/17/15). 


\section{CONCLUSION}

The rheological measurements for the sample P2 with lower starch content and higher water content of the formula, at higher temperature $\left(60^{\circ} \mathrm{C}\right)$, shows that the dependence between viscosity and share rate tends to linearity, while for a lower temperature $\left(30^{\circ} \mathrm{C}\right)$ the dependence between viscosity and share rate does not comply with the Newtonian model.

From the viscosity measurements performed on packaging samples based on native starch we observed a dependence of viscosity on temperature, concentration and share rates. An alghorithm of mathematical analysis of data obtained allows a separation of contribution of each variable to the viscosity and a single mathematical formula contains these contributions. The equation obtained is a preliminary

Acknowledgments. This work was supported by CNCSIS -UEFISCDI, project number PN II - IDEI code $284 / 2011$ and $307 / 2011$

\section{REFERENCES}

1. Bastioli, C.(2000) Global status of the production of biobased packaging materials, Proceedings of The Food Biopack Conference, Denmark, Copenhagen, p.2-7

2. Ferguson, J., Z. Kemblowski. (1992).Applied Fluid Rheology. Elsevier. London

3. Mitrus M., Moscicki L.(2014) Extrusion-cooking of starch protective loose-fill foams. Chemical engineering research and design. 92: 778-783

4. Nagy, E.M., M. Todica, C. Cota, V.C. Pop, N. Cioica, O. Cozar. (2015).Investigation of water degradation effect on some starch-based plastics. Proceedings of the $43^{\text {rd }}$ International Symposium on Agricultural Engineering "Actual Tasks on Agricultural Engineering", Opatija, Croatia. 755-762

5. Rosa D. S., Carvalho C. L., Gaboardi F., at all. (2008). Evaluation of enzymatic degradation based on the quantification of glucose in thermoplastic starch and its characterization by mechanical and morphological properties and NMR measurements. Polymer Testing, 27: 827-834

6. Todica M. (2005). Proprietati fizice ale polimerilor, Presa Universitară Clujeană, ISBN-973-610-376-5.

7. Vert M, Santos ID, Ponsart S, Alauzet N, Morgat JL, Coudane J (2002). Degradable polymers in a living environment: where do you end up? Polym Int. 51:840-844 